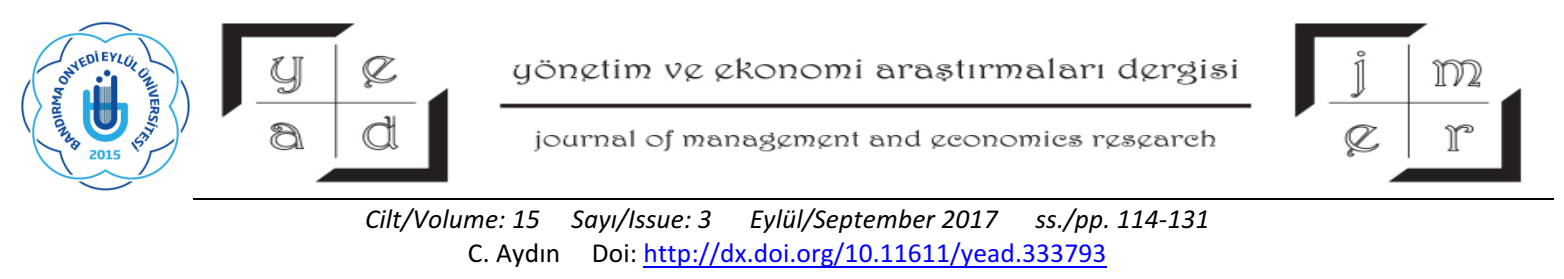

\title{
TÜRKİYE'DE BÖLGESEL ENFLASYONUN BÖLGESEL İŞSİZLİK VE BÜYÜME ÜZERİNE ETKİSI: PANEL YUMUŞAK GEÇIŞLİ REGRESYON YAKLAŞIMINDAN YENİ KANITLAR
}

\author{
Yrd.Doç.Dr. Celil AYDIN
}

\begin{abstract}
$\ddot{O Z Z}$
Bu çalışmada, 2005-2013 dönemi için Türkiye'de bölgesel düzeyde işsizlik ve ekonomik büyüme arasındaki ilişkide enflasyonun etkisi, enflasyon oranını eşik değişkeni olarak kullanan Panel Yumuşak Geçişli Regresyon analiz yöntemi ile incelenmiştir. Analiz sonuçlarına göre, enflasyon eşik düzeyi \%7.98 olarak tahmin edilmekte ve Türkiye'de enflasyon oranı eşiğin altında iken büyüme oranın artması işsizliği azaltmaktadır. Diğer taraftan, enflasyon oranı eşiğin üzerinde iken büyüme oranın artması işsizliği arttırmaktadır. Yüksek büyüme hızının ve düşük işsizlik oranının sağlanması uzun dönemde fiyat istikrarına bağll olduğu görülmektedir. Bu bağlamda fiyat istikrarl, uygulamaya konulan para politikalarının etkinliğinin artırllmasında ve istikrarın sağlanmasında hayati bir rol oynayan sürdürülebilir büyüme için önem arz etmektedir.
\end{abstract}

Anahtar kelimeler: Enflasyon eşik düzeyi, işsizlik, ekonomik büyüme, Panel Yumuşak Geçişli Regresyon

JEL Sinıflandırması: E24, E31, O11, O40

\section{THE IMPACT OF REGIONAL INFLATION ON THE RELATIONSHIP BETWEEN REGIONAL UNEMPLOYMENT AND GROWTH IN TURKEY: NEW EVIDENCE FROM A PANEL SMOOTH TRANSITION REGRESSION APPROACH}

\begin{abstract}
In this study, the effect of regional inflation on the relationship between regional unemployment and economic growth in Turkey was investigated for the period 2005-2013 using Panel Smooth Transition Regression analysis, which takes into account the inflation rate threshold level. According to the analysis results, the estimated value of the inflation threshold level is $7.98 \%$, and below the threshold an increase in economic growth beyond the threshold leads to a decrease in unemployment rates in Turkey. On the other hand, when the inflation rate is above the threshold, an increase in economic growth leads to an increase in unemployment rates. It appears that ensuring high economic
\end{abstract}

\footnotetext{
" Bandırma Onyedi Eylül Üniversitesi, Balıkesir/Türkiye, caydin@bandirma.edu.tr
} 
Yönetim ve Ekonomi Araştırmaları Dergisi / Journal of Management and Economics Research

Cilt/Volume: 15 Sayı/Issue: $3 \quad$ Ey/ül/September 2017 ss./pp. 114-131

C. Aydın Doi: http://dx.doi.org/10.11611/yead.333793

growth and low unemployment rate depends on price stability in the long term. In this regard, price stability is crucial for achieving sustainable growth, which plays a crucial role in increasing the efficiency of implemented monetary policies and assuring stability.

Keywords: Inflation threshold level, unemployment, economic growth, Panel Smooth Transition Regression

JEL Codes: E24, E31, O11, O40

\section{GIRIŞ}

Üretimi arttırmak, tam istihdama ulaşmak ve fiyat istikrarını sağlamak politika yapıcılarının öncelikli hedefleri arasında yer almaktadır. Buna karşın "politika yapıcıların fiyat istikrarını sağlama göreviyle beraber işsizlik oranlarını düşürme ve tam istihdamı gerçekleştirme hedeflerine ulaşmaları mümkün müdür?” sorusuna net bir cevap bulmak kolay değildir. Bu hedeflerin birbirleriyle çeliştiğine yönelik tartışmalar akademik ve siyasi çevrelerde sıklıkla gündeme gelmektedir. Literatürde iktisadi amaçların uyuşmazlığı olarak da bilinen bu tartışmaların temelinde, enflasyonun düşürülmesi için uygulanan politikaların en önemli maliyeti olarak işsizlik oranlarını artırdığı yer almaktadır. Aynı şekilde, işsizliği düşürmek ve ekonomide tam istihdamı sağlamak amacıyla uygulanan politikaların ekonomilerde enflasyona neden olduğuna yönelik tartışmalar sürmektedir. Son dönemde bu tartışmalar, farklı bir boyut kazanarak söz konusu makroekonomik hedefler arasındaki çelişkilerin özellikle kısa dönemde daha net bir biçimde ortaya çıktığı, ancak uzun döneme geçildikçe çelişkilerin yumuşamaya başladığ1 yönünde sürmektedir. Bunun en belirgin örneği işsizlik ve enflasyon arasında zıt yönlü bir ilişki olduğunu öne süren Phillips (1958)'in gerçekleştirdiği çalışmalardan yola çıkılarak geliştirilen Phillips Eğrisi analizlerinde görülmektedir. Phillips Eğrisi analizleri enflasyon artışına karşın işsizliğin düşeceği veya işsizlik arttıkça enflasyonun azalacağını göstermektedir. Ancak son yıllarda yapılan araştırmalar enflasyon-işsizlik ilişkisinin uzun dönemde bu kadar keskin tersine bir görünüm içinde olmadığını ortaya koymaktadır. Phillips Eğrisi’ne getirilen eleştirilerin başında söz konusu eğrinin, iktisadi karar birimlerin beklentilerini dikkate almamış olması yer almaktadır. Bu eleştiriler bağlamında yapılan çalışmalar, ekonomideki karar birimlerin beklentilerinin, enflasyon-büyüme-işsizlik ilişkisi üzerinde önemli bir faktör olduğunu göstermektedir. İktisadi çevrelerin ileriye dönük beklentilerinin değişmesine bağlı olarak büyümenin, istihdamın artmasına ve işsizliğin azalmasına olan katkısı da değişmektedir.

Enflasyonun en belirgin etkileri, tüketicilerin ve yatırımcıların karar alma aşamasında ortaya çıkmaktadır. Enflasyon oranının yüksek düzeyde seyretmesi ekonomide belirsizliğe neden olmakta ve iktisadi karar birimlerinin ileriye dönük kararlarını etkilemektedir. Bu durum karar birimlerini tüketim ve yatırım konularında kararsızlığa itmektedir. Fiyat istikrarı, yüksek enflasyon düzeyinin neden olduğu 
Yönetim ve Ekonomi Araştırmaları Dergisi / Journal of Management and Economics Research

Cilt/Volume: 15 Sayı/Issue: $3 \quad$ Ey/ül/September 2017 ss./pp. 114-131

C. Aydın Doi: http://dx.doi.org/10.11611/yead.333793

belirsizliğin ortadan kalkmasına yardımcı olmakta ve sürdürülebilir ekonomik büyümeye katkıda bulunmaktadır. Böylelikle tam istihdama ulaşma hedefi ile enflasyon hedefi birbiri ile çelişmemekte ve uzun dönemde enflasyon hedefinin gerçekleştirilmesi, tam istihdam hedefinin gerçekleşmesinde önemli bir rol oynamaktadır (TCMB, 2013). Fiyat istikrarının sağlanması ve korunması uzun dönemde büyüme ve istihdam için uygun ortamı oluşturmakta ve işsizliğin azalmasına katkı sağlamaktadır.

Fiyatlar, piyasa ekonomilerinde maliyetler ve talep konusunda temel bilgi kaynăg 1 olma özelliğine sahiptir. Ancak enflasyon, fiyatların kaynak tahsisi konusunda bir sinyal olarak kullanılmasına engel olmaktadır. Enflasyonist ortamda iktisadi karar birimleri, tüketim ve yatırım kararlarında fiyatlarda meydana gelen değişimleri kolayca ayırt edememekte ve sağlıklı karar verebilmek için yeterli bilgiye sahip olamamaktadırlar. $\mathrm{Bu}$ sebeple enflasyonist süreçte piyasa katılımcıları, uzun dönemli yatırım planları yapma konusunda karar vermede büyük zorluk ve risklerle karşılaşmaktadırlar. Yüksek enflasyona sahip ülkelerde tasarruf sahipleri ve yatırımcılar yatırımlardan elde ettikleri getiriyi enflasyon riskinden korumak için olması gerekenden daha yüksek getiri talep etmektedirler. Bu durum faiz oranlarının yükselmesine ve yatırım maliyetlerinin artmasına neden olmaktadır. Faizlerin yükselmesi, yatırımları azaltmakla birlikte finansal piyasalarda istikrarsızlığı artabilmekte ve ülke kalkınmasını olumsuz yönde etkileyebilmektedir (White, 2006). Ayrıca, enflasyonist bir ortamda paranın satın alım gücü sürekli düştüğünden bireyler enflasyonun olumsuz etkilerinden kurtulabilmek için üretken yatırımlardan altın, döviz, gayrimenkul gibi diğer kıymetlere yönelebilmektedir. Enflasyona karşı yüksek koruma sağladığı düşünülen altın, döviz, gayrimenkul gibi varlıklara yönelim, üretken sektörü olumsuz etkilemekte ve uzun dönemde daha düşük bir ekonomik büyümeye neden olmaktadır. Fiyatlardaki dalgalanmalara bağlı oluşan istikrarsız büyüme, kalıcı bir işgücü istihdamı yaratmaya engel oluşturmaktadır. Bu sebeple enflasyon, sürdürülebilir büyümenin yüksek oranlarda gerçekleşmesinin ve ekonomik istikrarın sağlanmasında önemli bir engel olarak ortaya çıkmaktadır (White, 2006). İktisadi karar birimlerinin yatırım, tasarruf ve tüketime ilişkin kararlarında dikkate almayacakları ölçüde düşük bir enflasyon oranını ifade eden fiyat istikrarı, karar birimlerine göreli fiyatları kolaylıkla karşılaştırma olanağı sağlamaktadır. Bu durum, yatırım ve tüketim kararlarının daha sağlıklı bir şekilde verilmesini ve dolayısıyla ülke kaynaklarının daha verimli alanlara yönlendirilmesini sağlamaktadır. Böylelikle büyüme potansiyeli ve istihdam imkânı artmaktadır.

İşsizlik sadece ekonomik bir sorun olmanın ötesinde, çok yönlü sosyal yansımaları olan bir sorun yumağıdır. İşsizlik, küresel krizlerle birlikte sadece az gelişmiş ya da gelişmekte olan ekonomilerin sorunu olmaktan çıkarak, tüm dünya ekonomilerinin gündemini meşgul eden en önemli ortak sorunlardan biri haline gelmiştir. İşsizliğin azaltılmasına yönelik çözümün giderek zorlaştığı ve yüksek büyüme hızının gerçekleşmesinin dahi işsizliğin çözümüne sınırlı seviyede katkıda bulunduğu bir durum yaşanmaktadır. Bu bakımdan Türkiye'de son dönemlerde yaşanan ekonomik gelişmelerin işgücü 
Yönetim ve Ekonomi Araștırmaları Dergisi / Journal of Management and Economics Research

Cilt/Volume: 15 Sayı/Issue: $3 \quad$ Ey/ül/September 2017 ss./pp. 114-131

C. Aydın Doi: http://dx.doi.org/10.11611/yead.333793

piyasası ve dolayısıyla istihdam üzerindeki etkileri oldukça tartışmalıdır (Ataman, 2006). İşsizlikle ilgili tartışmaların başında istihdam yaratmayan büyüme tartışması gelmektedir.

Türkiye'de 1990'lı yılların sonlarına doğru finansal piyasalarda istikrarın bozulması ve inişli çıkışlı bir büyüme trendi içine girilmesi sonucunda 2000'li yılların başında bir dizi önemli ekonomik krizler yaşanmıştır. Bu bağlamda, Türkiye ekonomisinin istikrara kavuşturulması ve sürdürülebilir bir ekonomik büyüme eğilimine girebilmesi için makroekonomik dengelerde ortaya çıkan bozulmaların bir an önce giderilmesi amacıyla gerekli alanlarda yapısal reformların yapılması ihtiyacı doğmuştur. Bunun üzerine 2001 sonrası dönemde ekonominin süratle istikrara kavuşturulması ve yeniden sürdürülebilir büyüme trendine geçilmesini hedefleyen politika ve tedbirler kapsamında bir dizi yapısal reformlar ve düzenlemeler hayata geçirilmiştir. Bu süreç ile birlikte sağlanan ekonomik ve siyasi istikrar Türkiye ekonomisinin istikrarlı bir ekonomik büyüme eğilimine girmesine katkı sağlamıştır. Ancak son yıllarda ekonomide yaşanan olumlu büyüme rakamlarına rağmen büyüme sürecinin istihdamı artırma ve işsizliği azaltmada etkisiz kaldığı gözlenmektedir (Ataman, 2006).

İssizliği, bir büyüme sorunu olarak görülmemesi gerekliliği Türkiye'de son yıllardaki istikrarlı büyüme sürecinde dahi yeterli istihdam yaratılamadığı ve işsizliğin azaltılamadığı realitesi ile ortaya çıkmaktadır. Ekonomik büyümenin istihdamı artırdığı ve işsizliğin azalmasına katkı sağladığı şeklindeki yaygın görüşün aksine, son dönemde yapılan ampirik çalışmalar, bu iki makroekonomik değişken arasındaki ilişkiyi sorgulamaktadırlar (Kılıç, 2003; Yılmaz, 2005; Yüceol, 2006; Ataman, 2006; Ceylan ve Şahin, 2010; Bayrak ve Esen, 2013; Şentürk ve Akbaş, 2014, Akay ve diğ, 2016; Aksu ve Başar, 2016; Esen ve diğ, 2017).

Bu çalışmalardan Kara ve Duruel (2005), 1980'li yıllardan günümüze yatırım imkânlarının tükenmesi, kırsal kesimden kentlere göç olgusu, hızlı nüfus artışı, verimlilik artışları, işgücü piyasasındaki yapısal katılıklar ve yaşanan siyasi istikrarsızlıkların, Türkiye'de büyümenin işsizliği azaltabilme kabiliyetini zayıflattığına vurgu yapmaktadırlar. Bayrak ve Esen (2013), özellikle 2001 krizi sonrası uygulanan yapısal reform sürecinde işsizliğin giderek daha büyük bir sorun haline geldiği ve gerçekleşen yüksek büyüme oranının dahi işsizliğin çözümüne sınırlı katkıda bulunmasını yapısal reformlara, özelleştirmelere, yüksek dışa bağımlılığa, tarım sektöründeki çözülmelere ve verimlilik artışına bağlamaktadır. $\mathrm{Bu}$ dönemde yapılan düzenlemelerin kısa dönemde iki değişken arasındaki ilişkiyi bozarken, uzun dönemde istikrarlı bir büyüme sürecinin istihdam olanaklarını arttıracağı vurgulanmaktadır. Ekonomik gelişmelerin işgücü piyasası üzerindeki etkilerinin sınırlı kalmasının nedeni olarak Şentürk ve Akbaş (2014), ithalata bağımlı bir üretim yapısına sahip Türkiye'nin üretimde kullanılan girdileri artırma yoluyla üretim artışı sağlamasına bağlamaktadır. Konuyu Türkiye açısından inceleyen Yılmaz (2005), Yüceol (2006), Ataman (2006), Ceylan ve Şahin (2010), Akay ve diğ. (2016) 
Yönetim ve Ekonomi Araștırmaları Dergisi / Journal of Management and Economics Research

Cilt/Volume: 15 Sayı/Issue: $3 \quad$ Ey/ül/September 2017 ss./pp. 114-131

C. Aydın Doi: http://dx.doi.org/10.11611/yead.333793

ve Aksu ve Başar (2016)'da çalışmalarında, ekonomik büyüme ile işsizlik arasındaki beklenen bağın zayıfladığı ya da koptuğu şeklindeki yaklaşımı destekleyen sonuçlar elde etmişlerdir.

Enflasyonist ortamın yarattığı belirsizlik, ekonomilerin uluslararası piyasalarda rekabet edebilme gücünü zayıflatmaktadır. Üreticiler maliyet yapılarını ulusal ve uluslararası düzeyde rekabet edebilir seviyelere çekebilmeleri ya da mevcut rekabet gücünü koruyabilmeleri adına işgücü maliyetlerini düşürerek üretimi öncelikle mevcut işgücüyle karşılama yoluna gidebilmektedirler. $\mathrm{Bu}$ dönemde işletmeler mevcut işgücünü daha fazla çalıştırarak üretimi sürdürmekte ve yeni işgücü konusunda çekingen davranabilmektedir (Boyer ve Petit, 1981; Havlik ve Landesmann, 2004; Belorgey vd., 2006 ve Marelli ve Signorelli, 2010). Firmalar, ancak fiyat istikrarının sağlandığı ve büyümenin sürekliliği konusunda emin olduktan sonra yeni istihdama gitmeyi tercih edeceklerdir. Bu süreçte işgücü verimliliğin artması, istihdam artışıla çatışma halinde olabilmektedir (Havlik ve Landesmann, 2004). Verimliliğin artması daha hızlı bir ekonomik büyümeye yol açmaktadır. Ancak verimlilik artışı kısa vadede dahi olsa iş imkânlarını kısıtlayabilmekte ve büyüme ile işsizlik arasındaki bağı zayıflatabilmektedir (Boyer ve Petit, 1981).

Esen ve diğ. (2017), Türkiye'de büyüme-istihdam/işsizlik etkileşimi üzerinde enflasyonun belirleyici bir rol oynayıp oynamadığını ve enflasyon eşik değerini 1980-2014 dönemi için araştırmışlardır. Ekonomik büyüme ve işsizlik arasındaki ilişkide enflasyon eşik değerini \%10.44 olarak tahmin etmişlerdir. Enflasyon oranı eşik değerin altında iken ekonomik büyümenin işsizliği azalttığ1, eşik değerin üzerinde ise büyümenin işsizlik üzerindeki azaltıcı etkisinin zayıfladığı sonucuna ulaşmışlardır. Diğer taraftan, uzun dönemde yüksek büyüme hızının ve düşük işsizlik oranın fiyat istikrarının sağlanması ile mümkün olabileceğini belirtmişlerdir.

İşsizlik-büyüme ilişkisinin geçerliliği konusunda yapılan uygulamalı çalışmalar ilişkinin doğrusal olduğu varsayımına dayanmakta ve ekonomik büyümenin arttığı ve azaldığı dönemlerde işsizlik üzerindeki mutlak etkisinin aynı olduğu düşünülmektedir. Diğer bir ifadeyle ilişkinin simetrik olduğu kabul edilmektedir. Doğrusal bir modelin seçilmesi sonucunda ise değişkenlerin ekonomik ortamın yapısından bağımsız aynı tür hareketler sergilediği ön varsayımı zorunlu olarak kabul edilmektedir. Oysa ekonomik değişkenlerin, hem kendi davranışları hem de aralarındaki ilişki doğrusal olmayan karakter taşıyabilmektedir. Bu tür bir asimetri, doğrusal olmayan karakterlidir ve doğrusal modeller ile yakalanamamaktadır. Doğrusal olmayan bir modelde ekonomik büyümenin işsizliğe, işsizliğin ekonomik büyümeye olan tepkisinin asimetrik olduğu kabul edilmektedir. Diğer bir ifade ile ekonomik büyümenin yüksek olduğu dönemdeki işsizliğe etkisi ile düşük olduğu dönemdeki etkisinin aynı olmadığıdır. Bunun yanı sıra, değişkenler arasındaki ilişkinin doğrusal olmama nedenleri olarak yapılan politika değişiklikleri, oluşan ekonomik krizler ve ekonomik ortamın yeniden yapılanması için gerçekleştirilen kurumsal değişiklikler, ekonomik değişkenlerin hem bireysel hareketlerinde hem de 
Yönetim ve Ekonomi Araștırmaları Dergisi / Journal of Management and Economics Research

Cilt/Volume: 15 Sayı/Issue: $3 \quad$ Ey/ül/September 2017 ss./pp. 114-131

C. Aydın Doi: http://dx.doi.org/10.11611/yead.333793

birbirleri ile olan ilişkilerinde değişimlere sebep olmaları sayılabilmektedir. Sonuç olarak, ekonomik ortamdaki bu tür değişimleri sağlıklı bir şekilde incelemek için doğrusal bir yapının yeterli olmayacağı açıktır. Bu nedenle, işsizlik-ekonomik büyüme ilişkisinde değişkenlerin zamana bağlı değişimleri ve karşılıklı etkileşimleri incelenirken doğrusal olmayan modelin kullanılması gerekmektedir.

Bu çalışma ekonomik büyümenin işsizlik üzerindeki etkisine 1şık tutan yeni kanıtlar sunmaktadır. Ayrıca çalışmada ekonomik büyüme-işsizlik ilişkisinde enflasyonun nasıl bir rol üstlendiği ve enflasyona ilişkin bir eşik değerinin olup olmadığını araştırılmaktadır. Bu ilişsi bir ülkenin enflasyon düzeyine bağlı olabilmektedir. Enflasyon düzeyi belirli bir eşik seviyesinin altında iken ekonomik büyümenin işsizlik üzerinde azaltıcı, üzerindeyken arttırıcı bir etki yaratabilmektedir. Çalışmanın bulguları politika yapıcılarına önemli öneriler sunabilir. Eğer yüksek enflasyon ortamında ekonomik büyümenin işsizliği arttırdığına veya enflasyona dair bir eşik seviyesi olduğuna ilişkin açık kanıt varsa, politika yapıcılar uygulanan para politikalarının etkinliğinin artırılması ve istikrarın sağlanması için enflasyonla mücadele çabalarında hedef enflasyon oranını belirlerken para politikası çerçevesinde eşik seviyesini göz önünde bulundurabilirler.

$\mathrm{Bu}$ araştırma literatüre üç açıdan katkı sağlamaktadır. Bu katkılardan ilki, çalışmada işsizlikbüyüme arasındaki doğrusal olmayan ilişkide enflasyonun rolü doğrusal olmayan panel veri analiz tekniklerinden Gonzalez, Terasvirta ve van Dijk (2005) tarafından geliştirilen Panel Yumuşak Geçişli Regresyon modelinin kullanılmasıdır. Bu analiz yöntemi Hansen (1999) tarafından geliştirilen Panel Eşik Regresyon modelinden farklı olarak regresyon parametrelerinin bir rejimden diğer rejime geçerken keskin ve ani değil de kademeli olarak yavaş bir şekilde değişmesine izin vermektedir. İkincisi, işsizlikbüyüme arasındaki doğrusal olmayan ilişkinin modellenmesinde quadratik modellerde kullanılabilmektedir. Bu yöntemin kullanılmasının önemli bir kısıtı bulunmaktadır. İşsizlik-büyüme ilişkisinde büyümenin karesinin quadratik modelde kullanılması, ekonomik büyümenin işsizlik üzerindeki etkisinin büyüme oranı seviyesine bağlı olarak monoton ve simetrik bir şekilde arttığı ve azaldığı şeklinde önsel bir sınırlama getirmektedir. Ayrıca, ilişkinin negatif aralıkları, pozitif aralıklarla karşılaştırıldığında mutlak etki açısından farklılık gösterebilmektedir. Bu bağlamda, çalışma ekonomik büyümenin işsizliği nasıl etkilediğine 1şık tutacak eşik etkisi kavramına dayalı bir regresyon modeli kullanmaktadır. Sonuncusu ise çalışmada kullanılan verilerin ülke düzeyinde değil de bölgesel düzeyde olmasıdır. Bölgesel verilerin kullanılması, bölgesel farklılıkların etkisinin modele dâhil olmasını sağlamaktadır.

Bu çalışma, Türkiye'de ekonomik büyüme stratejisinin önemli bir değişim geçirdiği 2001 sonrası dönemde bölgesel büyüme ile istihdam arasındaki ilişkinin zayıfladığı yönündeki tartışmalara katkı sağlamayı ve bölgesel büyüme-istihdam/işsizlik etkileşimi üzerinde bölgesel enflasyonun belirleyici bir rol oynayıp oynamadığı konusuna açıklık getirmeyi amaçlamaktadır. Bu amaç doğrultusunda 
Yönetim ve Ekonomi Araştırmaları Dergisi / Journal of Management and Economics Research

Cilt/Volume: 15 Sayı/Issue: $3 \quad$ Ey/ül/September 2017 ss./pp. 114-131

C. Aydın Doi: http://dx.doi.org/10.11611/yead.333793

çalışmanın ilk aşamasında, enflasyonun ekonomik büyüme-ilişkisi üzerindeki olası etkileri ele alınmıştır. İlerleyen bölümlerde, Türkiye'nin 2001 sonrası uygulanan büyüme stratejisi uygulamaya koyduğu 2005-2013 dönemini kapsayan bölgesel büyüme-işsizlik etkileşimi ve bu ilişkide bölgesel enflasyon için bir eşik olup olmadığı incelenecektir. Nihai aşamada ise analize ait ampirik bulguların mevcut literatüre olan uyumu değerlendirilecektir.

\section{MODEL}

Ekonomik büyüme ve işsizlik arasındaki ilişkinin açıklanmasında uygun bir teorik arka plana sahip olan Okun Yasası kullanılmaktadır. Bilindiği üzere ekonomik büyüme ve işsizlik ilişkisi Okun tarafından da belirtildiği gibi farklı yaklaşımlarla ifade edilebilmektedir (Knotek, 2007: 75). Bu yaklaşımlardan biri de bu ilişkiyi açıklayan fark versiyonudur. Fark versiyonu denklem (1)'deki gibi ifade edilmektedir:

$$
U_{t}-U_{t-1}=\beta_{0}+\beta_{1}\left(G D P_{t}-G D P_{t-1}\right)+e_{t}
$$

Denklem (1)'deki ifade düzenlendiğinde Denklem (2)'deki gibi gösterilebilmektedir;

$$
\Delta U_{t}=\beta_{0}+\beta_{1} \Delta G D P_{t}+e_{t}
$$

Denklem (2)'de $\Delta$ fark operatörü iken $U_{t}$ ve $G D P_{t}$ sırasıyla $t$ zamanındaki işsizlik oranı ile Gayri Safi Yurtiçi Hasıla'yı temsil etmektedir. $e_{t}$ ise beyaz gürültüye sahip olan hata terimini ifade etmektedir.

Bununla birlikte deneysel bir düzenlilik olarak değil de yasa olarak adlandırılan Okun yasası; hasılanın büyüme oranını, işsizlik oranındaki azalmaya çevirmek için uygun bir yöntem olarak kullanılabilmektedir (Barışık ve diğ. 2010). Bu kural sadece yaklaşık bir sonuç vermesine ve yıldan yıla çok kesin bir biçimde işlememesine karşın yine de büyümeden işsizliğe doğru anlamlı bir dönüştürme sağlamaktadır (Dornbusch ve Fischer, 1998:19).

\section{METODOLOJí}

Türkiye'de işsizliğin çözümünün giderek zorlaştığı ve yüksek büyüme hızının dahi işsizliğin çözümüne sınırlı katkıda bulunduğu bir durum yaşanmaktadır. Bu bakımdan Türkiye'de son dönem yaşanan ekonomik gelişmelerin özellikle bölgesel işgücü piyasası üzerindeki etkileri oldukça tartışmalıdır. Bu noktadan hareketle, bölgesel ekonomik büyüme ile bölgesel işsizlik oranı değişkenleri arasında bir kırılmanın yaşanıp yaşanmadığg diğer bir değişle, asimetrik bir ilişkinin var olup olmadığ1 ve bölgesel enflasyon düzeyinin bu kırılmalardaki etkisinin olabileceği düşüncesi çalışmanın çıkış noktası olmuştur.

Bilindiği üzere, ekonomilerde yurtiçi ve bölgesel piyasalarda meydana gelen sorunlar ve bu sorunlara yönelik yürütülen yapısal düzenlemeler, siyasi belirsizlikler, hükümet politikalarındaki 
Yönetim ve Ekonomi Araştırmaları Dergisi / Journal of Management and Economics Research

Cilt/Volume: 15 Sayı/Issue: $3 \quad$ Ey/ül/September 2017 ss./pp. 114-131

C. Aydın Doi: http://dx.doi.org/10.11611/yead.333793

değişiklikler gibi çeşitli faktörler, zaman serilerinde kırılmalara sebep olabilmektedir (Akgül ve Özdemir, 2012). Kırılmalar, ekonometrik modellerde doğrusal olmayan bir yapının ortaya çıkmasına neden olabilmektedir. Bu durum rejim değişikliklerini temsil edebilecek doğrusal olmayan modellerin ve bu modellere ilişkin tahmin yöntemlerinin gelişmesini sağlamıştır.

Bu çalışmada, Türkiye'de bölgesel bazda işsizlik düzeyi ile ekonomik büyüme arasındaki doğrusal olmayan ilişkide enflasyonun rolü panel veri analizi ile incelenmektedir. Panel veri analizinde değişkenler arasındaki doğrusal olmayan ilişkiyi analiz eden yöntemlerden biri Hansen (1999) tarafından geliştirilen Panel Eşik Regresyon (PER) yöntemidir. Bu yöntemde eşik değişkeninin bağımlı değişken üzerindeki etkisi eşiğin altındaki ve üzerindeki rejimlerde farklılık gösterebilmektedir. Bu durum eşik değişkeninin bağımlı değişken üzerindeki etkisini gösteren katsayının rejimlere göre farklı olmasını gerektirmektedir. PER yaklaşımında parametrelerin rejimler arasında ani olarak değişiklik gösterdiği varsayılmakta ve her bir rejim, tespit edilen eşik değerine göre birbirinden ayrılmaktadır. Ancak, parametrelerin rejimler arasında ani olarak değişiklik göstermesi iktisadi açıdan her zaman mümkün olmayabilmektedir (Güloğlu ve Nazlığlu, 2013). Bu nedenle bu çalışmada regresyon parametrelerinin bir rejimden diğer rejime geçerken keskin ve ani değil de kademeli olarak yavaş bir şekilde değişmesine izin veren ve Gonzalez, Terasvirta ve van Dijk (2005) tarafindan geliştirilen Panel Yumuşak Geçişli Regresyon (PYGR) modeli kullanılmıştır.

Bölgesel işsizlik ve ekonomik büyüme arasındaki doğrusal olmayan ilişkide bölgesel enflasyonun etkisinin incelenmesi amacıyla, denklem (2)'deki modelden hareketle iki rejimli sabit PYGR modeli oluşturulmuş ve denklem (3)'te gösterilmiştir:

$$
d U_{i, t}=\mu_{i}+\beta_{0} d G D P_{i, t}+\beta_{1} d G D P_{i, t} * g\left(q_{i, t} ; \gamma, \theta\right)+\varepsilon_{i, t}
$$

Denklem (3)'te $d U$ işsizlik artış hızını; $d G D P$ GSYİH büyüme oranını; $\varepsilon$ hata terimini; $\mathrm{t}=1,2$, ..., T zamanı; ve i=1, 2, 3.., N bölgeleri temsil etmektedir. $\mu_{i}$ bölgeye özgü sabit etkileri ve $q_{i}$ ise eşik değişkenini göstermektedir. Denklem (3)'te $g\left(q_{i, t} ; \gamma, \theta\right)$ geçiş fonksiyonu olarak kullanılmakta ve lojistik fonksiyon formunda denklem (4)' deki gibi ifade edilmektedir:

$$
g\left(q_{i, t} ; \gamma, \theta\right)=\left[1+\exp \left(-\gamma\left(q_{i, t}-\theta\right)\right)\right]^{-1}
$$

Denklem (4)'de $\theta$ parametresi $g\left(q_{i, t} ; \gamma, \theta\right)=0$ ve $g\left(q_{i, t} ; \gamma, \theta\right)=1$ 'e denk gelen iki rejim arasındaki eşik parametresi iken $\gamma$ (düzleştirme parametresi) ise geçiş fonksiyonunun değerindeki değişmenin düzlüğünü, diğer bir ifade ile bir rejimden diğer rejime geçişi belirlemektedir. Düzleştirme parametresi sonsuza gittikçe $(\gamma \rightarrow \infty)$ geçiş fonksiyonundaki 0'dan 1'e doğru değişme, eşik değişkeninin $\theta$ 'ya eşit olduğu noktada bir rejimden diğer rejime geçiş PER modelinde olduğu gibi ani ve keskin bir şekilde olmaktadır. Bu durumda model PER yaklaşımı kullanılarak tahmin edilmektedir. 
Yönetim ve Ekonomi Araştırmaları Dergisi / Journal of Management and Economics Research

Cilt/Volume: 15 Sayı/Issue: $3 \quad$ Ey/ül/September 2017 ss./pp. 114-131

C. Aydın Doi: http://dx.doi.org/10.11611/yead.333793

Düzleştirme parametresinin sıfira yaklaştı̆̆ bir durumda ise $(\gamma \rightarrow 0)$ geçiş fonksiyonu bir sabite eşit olmakta ve düzleştirme parametresinin sıfıra eşit olduğu noktada $(\gamma=0)$ model doğrusal forma indirgenmektedir. Böyle bir durumda model panel kesit-içi tahmincisi kullanılarak tahmin edilmektedir (Fouquau et al., 2008; 287-288).

Geçiş fonksiyonu, geçiş değişkeninin sürekli fonksiyonu olduğu gibi 0 ve 1 arasında bir değer almaktadır. Denklem (3)'te geçiş fonksiyonu 0 değerini aldığında $\left(g\left(q_{i, t} ; \gamma, \theta\right)=0\right)$ regresyon katsayısı $\beta_{0}$ değerini; 1 değerini aldığında ise $\left(g\left(q_{i, t} ; \gamma, \theta\right)=1\right)$ ise regresyon katsayısı $\beta_{0}+\beta_{1}$ değerini almaktadır. Diğer taraftan geçiş fonksiyonu 0 ile 1 değeri arasında bir değer aldığında ise $(0<$ $\left.g\left(q_{i, t} ; \gamma, \theta\right)<1\right)$ regresyon katsayısı $\beta_{0}$ ve $\beta_{1}$ 'in ağırlıklı ortalaması şeklinde hesaplanmaktadır. $\mathrm{Bu}$ nedenle PYGR modelinde katsayıları doğrudan yorumlamak yerine katsayı işaretlerinin yorumlanması tercih edilmektedir (Fouquau et al., 2008). Diğer bir ifadeyle bağımsız değişkenin bağımlı değişkenin üzerindeki etkisinin pozitif/negatif olduğu söylenmekte ve zamana göre değişen esneklikler yorumlanmaktadır (Güloğlu ve Nazlıoğlu, 2013).

PYGR modeli iki rejimli olabileceği gibi ikiden fazla rejimlide olabilmektedir. Bu durumda denklem (1)'deki modele ilişkin ikiden fazla rejimli PYGR modeli denklem (5)'teki gibi ifade edilmektedir:

$$
d U_{i, t}=\mu_{i}+\beta_{0} d G D P_{i, t}+\sum_{j=1}^{r} \beta_{j} d G D P_{i, t} * g_{j}\left(q_{i, t}^{(j)} ; \gamma_{j}, \theta_{j}\right)+u_{i, t}
$$

İkiden fazla rejimli PYGR modelinde kullanılan geçiş fonksiyonu denklem (6)'daki gibi ifade edilmektedir.

$$
g\left(q_{i, t} ; \gamma, \theta\right)=\left[1+\exp \left(-\gamma \prod_{j=1}^{m}\left(q_{i, t}-\theta_{j}\right)\right)\right]^{-1}, \gamma>0, c_{1} \leq c_{2} \leq \cdots \leq c_{m}
$$

İkiden fazla rejimli PYGR modelinde geçiş (eşik) değişkeninin $(q)$ açıklayıcı değişkenden farklı olduğu bir durumda ( $q$ = inflation ${ }_{i, t}$ ) esneklik değeri denklem (7)'deki gibi hesaplanmaktadır:

$$
e_{i, t}=\frac{\partial d U_{i, t}}{\partial d G D P_{i, t}}=\beta_{0}+\sum_{j=1}^{r} \beta_{j} * g_{j}\left(q_{i, t}^{(j)} ; \gamma_{j}, \theta_{j}\right)
$$

PYGR analizinde sırasıyla doğrusallığın test edilmekte, rejim sayısının belirlenmenmekte $(r)$ ve modelin tahmin edilmektedir (Fouquau et al., 2008). Doğrusallık $\gamma=0$ veya $\beta_{0}=\beta_{1}$ sifır hipotezlerinin sınanması ile yapılmakta Ancak her iki durumda model sıfır hipotezi altında tanımlı olmayan parametrelere sahip olduğu için test istatistiği standart olmamaktadır. $\mathrm{Bu}$ nedenle geçiş fonksiyonu yerine $\gamma=0$ için birinci derece Taylor açılımı uygulanmaktadır. Doğrusallık sınamasında sıfır hipotez doğrusal model iken alternatif hipotez ise PYGR modeldir. Bu hipotezler standart Fistatistiği ile test edilmektedir. Standart F-istatistiğine göre sıfır hipotezinin reddedilmesi PYGR 
Yönetim ve Ekonomi Araştırmaları Dergisi / Journal of Management and Economics Research

Cilt/Volume: 15 Sayı/Issue: $3 \quad$ Ey/ül/September 2017 ss./pp. 114-131

C. Aydın Doi: http://dx.doi.org/10.11611/yead.333793

modelinin kullanılmasını gerektirmektedir. Doğrusal model hipotezinin reddedilmesinden sonraki aşama ise rejim sayısının belirlenmesi aşamasıdır. Bu aşamada, ilk olarak $r=r^{*}=1$ sıfır hipotezi, $r=r^{*}+1$ alternatif hipotezine karşı sınanmaktadır. Sıfır hipotezi kabul edilirse süreç sona ermektedir. Sıfır hipotezinin reddedilmesi durumunda ise $r=r^{*}+1$ sıfır hipotezi, $r=r^{*}+2$ alternatif hipotezine karş1 test edilmektedir. Rejim sayısının belirlenmesi aşaması sıfır hipotezinin ilk kez kabul edilmesine kadar devam etmektedir (Fouquau et al., 2008). PYGR analizinde son aşama tahmin aşamasıdır. Bu aşamada ilk olarak paneli oluşturan yatay kesitlere ait sabit ekiler değişkenlerin zaman ortalamalarından çıkarılmakta ve sonra dönüştürülmüş model doğrusal olmayan EKK ile tahmin edilmektedir (Gonzalez et al., 2005).

\section{VERİ SETİ VE AMPIRİK SONUÇLAR}

\subsection{Veri Seti}

Bu çalışmada Türkiye'de bölgesel bazda işsizlik düzeyi ile ekonomik büyüme arasındaki doğrusal olmayan ilişkide enflasyonun rolü 2005-2013 dönemi itibariyle Panel Yumuşak Geçişli Regresyon ile incelenmektedir. Çalışmada IBBS-2 sınıflandırmasına göre Türkiye'deki 26 bölgeye ilişkin yıllık veriler kullanılmaktadır. Modelde işsizlik artış hızı $(d U)$ bağımlı değişken; kişi başına GSYİH büyüme oranı $(d G D P)$ bağımsız değişken olarak kullanılmıştır. Ayrıca, işsizlik düzeyi ile ekonomik büyüme arasındaki ilişkide enflasyonun etkisini araştırmak amacıyla enflasyon oranı $(\pi)$ eşik değişkeni olarak modelde yer almıştır. Enflasyon oranı Tüketici Fiyat Endeksinde (TÜFE) meydana gelen yıllık değişimi göstermektedir. Çalışmada kullanılan değişkenlere ilişkin veriler Türkiye İstatistik Kurumu (TÜİK) veri tabanından elde edilmiştir. Tablo 1'de değişkenlere ilişkin betimleyici istatistikler verilmiştir.

Tablo 1. Değişkenlerin düzey değerlerine ilişkin betimleyici istatistikler

\begin{tabular}{lrrr}
\hline Örneklem & $d U$ & $d G D P$ & $\pi$ \\
\hline Ortalama & -0.122 & 0.084 & 8.088 \\
Standart. Sapma. & 2.322 & 0.115 & 1.378 \\
Maksimum. & 10.600 & 0.267 & 12.030 \\
Minimum. & -6.000 & -0.245 & 4.091 \\
Gözlem Sayıs1 & 234 & 234 & 234 \\
\hline
\end{tabular}

Tablo 1'de görüldüğü gibi işsizlik artış oranı ve kişi başına GSYİH büyüme oranı değişkenlerine ilişkin ortalama değerler sırasıyla -0.122 ve 0.084 'dür. Ayrıca, kişi başına GSYİH büyüme oranı ile işsizlik artış oranı arasında istatistiksel olarak anlamlı ve negatif korelasyon bulunmaktadır (-0.299). Bu 
Yönetim ve Ekonomi Araştırmaları Dergisi / Journal of Management and Economics Research

Cilt/Volume: 15 Sayı/Issue: $3 \quad$ Eylül/September $2017 \quad$ ss./pp. 114-131

C. Aydın Doi: http://dx.doi.org/10.11611/yead.333793

sonuçlar düşük işsizlik oranına sahip olan bölgelerin daha yüksek bir büyüme hızına sahip olduğunu göstermektedir.

\subsection{Ampirik Sonuçlar}

Türkiye'de bölgesel işsizlik düzeyi ile ekonomik büyüme arasındaki doğrusal olmayan ilişkide bölgesel enflasyonun rolünün incelendiği bu çalışmada ilk olarak yatay kesitler (bölgeler) arasındaki bağımlılık incelenmiştir. Paneli oluşturan yatay kesitler arasındaki bağımlılı̆̆ın dikkate alınıp alınmaması elde edilecek tahmin sonuçlarını önemli derecede etkilemesi nedeniyle ilk olarak serilerde ve modelde yatay kesit bağımlılığının varlığının test edilmesi gerekmektedir. Ayrıca bu durumun birim kök testlerinin seçiminde dikkate alınması gerekmektedir. Aksi takdirde modellere ilişkin yapılan tahminler hatalı olabilecektir. Bundan dolayı çalışmada ilk olarak yatay kesit bağımlılığının varlığı, Breusch-Pagan (1980) tarafindan bulunan ve Pesaran vd. (2008) tarafından sapması düzeltilen LMadj $_{\text {adj }}$ (Adjusted Lagrange Multiplier) testiyle incelenmiş ve elde edilen sonuçlar Tablo 2'de gösterilmiştir.

Tablo 2. Yatay Kesit Bağımlılı̆̆ı Testi

\begin{tabular}{llll}
\hline Örneklem & \multicolumn{1}{c}{$d U$} & \multicolumn{1}{c}{$d G D P$} & \multicolumn{1}{c}{ Model } \\
\hline$C D_{B P}$ & $774.344^{* * *}$ & $651.176^{* * *}$ & $728.063^{* * *}$ \\
$C D_{L M}$ & $17.625^{* * *}$ & $12.794^{* * *}$ & $15.809^{* * *}$ \\
$C D$ & $-1.873^{* *}$ & $-1.195^{*}$ & $17.565^{* * *}$ \\
$L M_{a d j}$ & $11.287^{* * *}$ & $3.614^{* *}$ & $1.284^{*}$ \\
\hline
\end{tabular}

*, **, *** surasıyla $\% 10, \% 5$ ve $1 \%$ anlamlılık seviyelerini göstermektedir. $C D_{B P}:$ Breusch and Pagan
testi, $C D_{L M}:$ Pesaran $2004 \mathrm{CD}$ lm testi, $C D$ :Pesaran $2004 \mathrm{CD}$ testi ve $L M_{a d j}:$ Bias-adjusted CD testi.

Tablo 2'deki işsizlik artış hızı ve kişi başına GSYIH büyüme oranı serilerine ilişkin test istatistiklerine göre "yatay kesit bağımlılı̆̆ 1 yoktur" şeklinde kurulan boş hipotez kuvvetli biçimde reddedilmiştir. Serilerde ve modelde yatay kesit bağımlılığının olduğuna karar verilmiştir. Bu sonuç bölgelerden birine gelen bir şokun diğerlerini de etkilediğini göstermektedir. Ayrıca, analizin sonraki bölümlerinde kullanılacak yöntemler seçilirken yatay kesit bağımlılığını dikkate alan test yöntemlerinin kullanılması gerekmektedir. Bu nedenle, çalışmanın ilerleyen bölümlerinde, serilerin durağanlığı yatay kesit bağımlılığını dikkate alan Moon and Perron (2004) ikinci nesil panel birim kök testi ile incelenmiş ve elde edile sonuçlar Tablo 3'te gösterilmiştir. Tablo 3'te elde edilen sonuçlara göre örneklemin tamamına ilişkin "serilerin birim kök içerdiği” şeklinde kurulan boş hipotez, işsizlik artış hızı ve kişi başına GSYİH büyüme oranı serileri için reddedilmektedir. Bu durum serilerin düzey değerlerinde $(I(0))$ durağan olduklarını göstermektedir. 
Yönetim ve Ekonomi Araştırmaları Dergisi / Journal of Management and Economics Research

Cilt/Volume: 15 Sayı/Issue: $3 \quad$ Ey/ül/September $2017 \quad$ ss./pp. 114-131

C. Aydın Doi: http://dx.doi.org/10.11611/yead.333793

Tablo 3. Moon and Perron (2004) panel birim kök testi sonuçları

\begin{tabular}{lll}
\hline Örneklem & \multicolumn{1}{c}{$d U$} & $d G D P$ \\
\hline$\hat{r}$ & 3 & 2 \\
$t_{a}^{*}$ & $-13.436^{* * *}$ & $-19.917^{* * *}$ \\
$t_{b}^{*}$ & $-8.136^{* *}$ & $-11.930^{* * *}$ \\
$\hat{\rho}_{\text {pool }}^{*}$ & 0.054 & -0.233 \\
\hline
\end{tabular}

$\hat{r}$ temel bileşen sayısını, $t_{a}^{*}$ ve $t_{b}^{*}$ birim kök test istatistiklerini göstermektedir. *,

$* *, * * *$ sirasıyla $\% 10, \% 5$ ve $1 \%$ anlamlılık seviyelerini göstermektedir.

Modelde kullanılan değişkenlerin düzey değerlerinde durağan olduklarının tespit edilmesinden sonraki aşama doğrusal modelin doğrusal olmayan modele karşın test edilmesidir. Örneklemin tamamına ilişkin doğrusallığın test edilmesi ve geçiş fonksiyonu sayısının belirlenmesi için hesaplanan Wald Testi $(L M)$, Fisher Testi $\left(L M_{F}\right)$ ve LRT Testi $(L R T)$ sonuçları Tablo 4'te gösterilmiştir.

Tablo 4. Doğrusallık testi

\begin{tabular}{lc}
\hline Eşik Değişkeni $(\pi)$ & Örneklem \\
\hline$H_{0}:$ D ğrusal Model & \\
$H_{1}:$ En Az Bir Eşikle PYGR Model \\
$L M$ & 14.592 \\
& $(0.000)$ \\
$L M_{F}$ & 13.767 \\
& $(0.000)$ \\
$L R T$ & 19.067 \\
& $(0.000)$ \\
\hline Parantez içindeki değerler olasılık değerleridir. ${ }^{* *}$ ve ${ }^{* * *}$ sirasılyla \\
$\% 5$ ve $1 \%$ anlamll11k seviyelerini göstermektedir.
\end{tabular}

Tablo 4'te görüldüğü gibi $L M, L M_{F}$ ve $L R T$ test sonuçlarına göre örneklemin tamamında sıfır hipotezi \%1 anlamlılık düzeyinde reddedilmektedir. Böylece, modelin doğrusal olmayan en az bir eşik etkisi içerdiği alternatif hipotezi kabul edilmiş ve kişi başına GSYİH büyüme oranının işsizlik artış hızı üzerindeki etkisinin analizinde doğrusal model kullanılmasının uygun olmadığı sonucuna ulaşılmıştır. Doğrusal model hipotezinin reddedilmesiyle birlikte analizde bir sonraki aşama rejim sayısının belirlenmesidir. Uygun rejim sayısının belirlenmesi amacıyla örneklemin tamamı için $L M, L M_{F}$ ve $L R T$ testleri tekrar edilmiş ve elde edilen sonuçlar Tablo 5’te gösterilmiştir. 
Yönetim ve Ekonomi Araştırmaları Dergisi / Journal of Management and Economics Research

Cilt/Volume: 15 Sayı/Issue: $3 \quad$ Eylül/September $2017 \quad$ ss./pp. 114-131

C. Aydın Doi: http://dx.doi.org/10.11611/yead.333793

Tablo 5. PYGR modele ilişkin eşik sayısının belirlenmesi

\begin{tabular}{ll}
\hline Eşik Değişkeni $(\pi)$ & Örneklem \\
\hline$H_{0}: r=1$ vs $H_{1}: r=2$ & \\
$L M$ & 0.001 \\
& $(0.977)$ \\
$L M_{F}$ & 0.001 \\
& $(0.978)$ \\
$L R T$ & 0.001 \\
& $(0.977)$ \\
\hline Parantez içindeki değerler olasılık değerleridir. ** ve ${ }^{* * *}$ sirasılyla \%5 ve $1 \%$ \\
anlamllık seviyelerini göstermektedir.
\end{tabular}

Tablo 5'te görüldüğü gibi modelin "bir eşik etkisi içerdiği”" sıfır hipotezi örneklemin tamamı için reddedilememiştir. Böylece gelişmiş örneklemin tamamına ilişkin modelin bir eşik etkisi içerdiğine ve iki rejimli PYGR modeli ile tahmin edileceğine karar verilmiştir. Bir sonraki aşamada bölgesel işsizlik düzeyi ile ekonomik büyüme arasındaki doğrusal olmayan ilişkide bölgesel enflasyonun rolünü gösteren denklem (3), iki rejimli PYGR modeliyle tahmin edilmiş ve tahmin sonuçları Tablo 6'da gösterilmiştir.

Tablo 6. PYGR modeli tahmin sonuçları

\begin{tabular}{ll}
\hline Eşik Değişkeni $(\pi)$ & Örneklem \\
\hline$d G D P_{1}$ & $-0.156^{* * *}$ \\
& $(0.028)$ \\
& $0.217^{* * *}$ \\
& $(0.062)$ \\
\hline Eşik Parametresi, $\theta$ & 7.980 \\
\hline Düzleştirme Parametresi, $\gamma$ & 0.672 \\
\hline $\begin{array}{l}\text { Parantez içindeki değerler standart sapma değerleridir. *** } 1 \% \\
\text { anlamlılık seviyesini göstermektedir. }\end{array}$
\end{tabular}

Tablo 6'da belirtildiği gibi düzleştirme parametresi oldukça küçük bir değer almaktadır (0.672). Düzleştirme parametresinin küçük bir değer alması, işsizlik artış hızı ile kişi başına GSYİH büyüme oranı arasındaki ilişkide bir rejimden diğer rejime geçişin keskin olmadığını ve yumuşak bir şekilde olduğunu göstermektedir. Bu durum şekil 1'de gösterilmiştir. 
Yönetim ve Ekonomi Araștırmaları Dergisi / Journal of Management and Economics Research

Cilt/Volume: 15 Sayı/Issue: 3 Ey/ül/September 2017 ss./pp. 114-131

C. Aydın Doi: http://dx.doi.org/10.11611/yead.333793

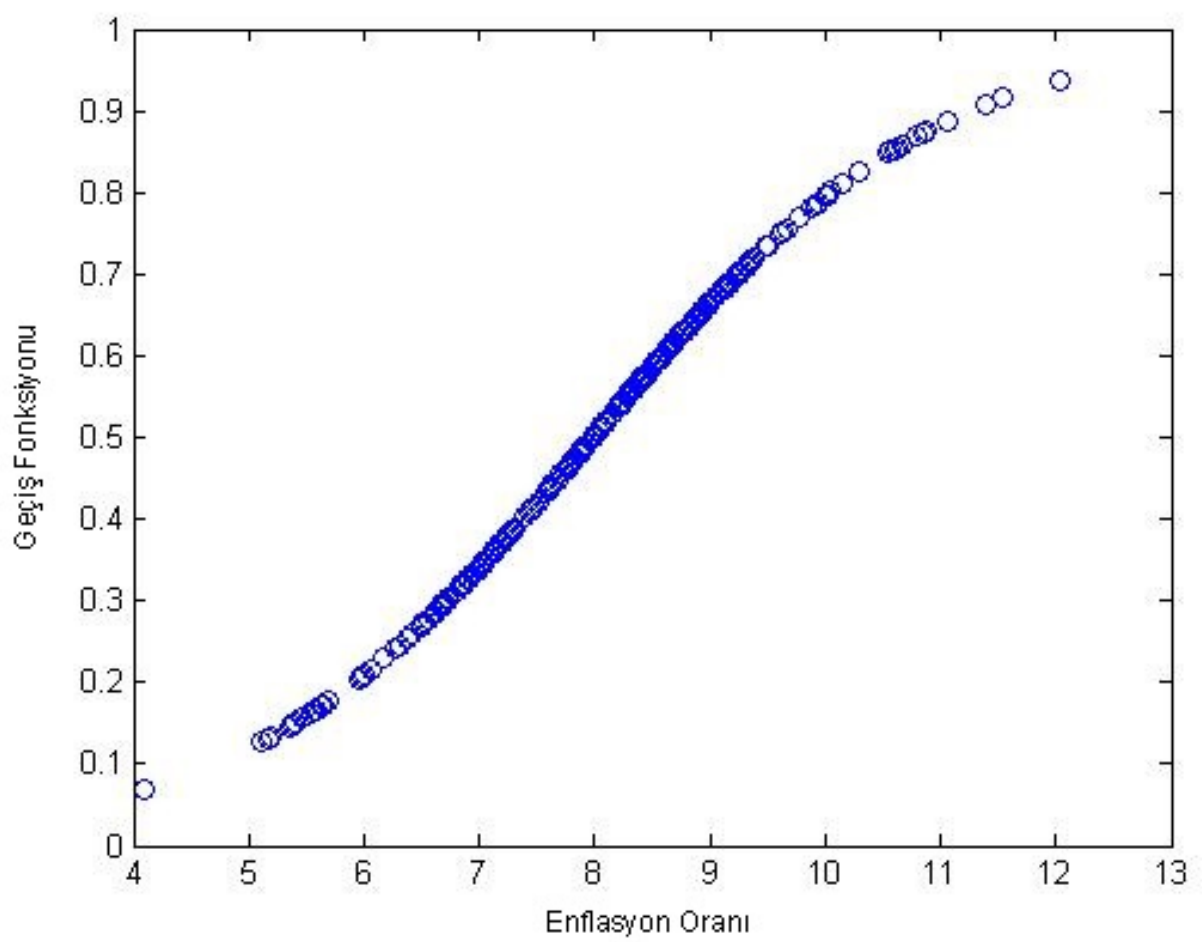

Şekil 1. PYGR modele ilişkin tahmin edilen geçiş fonksiyonu

Tablo 6'da görüldüğü gibi enflasyon oranına ilişkin eşik değeri \%7.98 olarak bulunmuştur. Türkiye için elde edilen eşik değeri ilgili literatürle uyumlu olduğu görülmektedir (Akgül ve Özdemir, 2012; Aydın ve diğ., 2016; Esen ve diğ, 2016; Aydın ve Odabaşığlu, 2017). Ayrıca Tablo 6'da enflasyon oranının eşik değerin altında olduğu ilk rejimde kişi başına GSYİH’nin tahmin edilen katsayısı $\left(\beta_{0}\right) \% 1$ anlamlılık düzeyinde istatistiksel olarak anlamlı ve negatiftir (-0.156). Enflasyon oranının eşik değerin üstünde olduğu ikinci rejimde ise $\beta_{0}$ ve $\beta_{1}$ toplamı ile ifade edilen katsayı istatistiksel olarak anlamlı ve pozitif olmaktadır (0.061). Diğer bir ifade ile bölgesel enflasyon oranının \%7.98'in altında gerçekleşmesi durumunda bölgede ekonomik büyümenin hızlanmasının işsizliği azaltacağı; enflasyon oranının \%7.98'in üzerinde gerçekleşmesi durumunda ise ekonomik büyümenin hızlanmasının bölgede işsizliği azaltmayacağı gibi düşük bir oranda da olsa arttırabileceği öngörülmektedir. Enflasyon oranı eşik değerin altında iken ekonomik büyümenin işsizliği azaltması, eşik değerin üzerinde ise işsizlik üzerindeki etkinin tersine dönmesi şu şekilde açıklanabilmektedir. İlk olarak fiyat istikrarının tam olarak sağlanamaması sonucu yaşanan yüksek enflasyon oranlarıdır. Enflasyonist ortamın yarattığı belirsizlik, firmaların ulusal ve uluslararası rekabet gücünün zayıflatmasına neden olabilmektedir. Bu durumda firmalar maliyet yapılarını rekabet edebilir seviyelere çekebilme adına işgücü maliyetlerini düşürerek üretimi öncelikle mevcut işgücüyle karşılama yani işgücünü daha fazla çalıştırma yoluna gidebilmektedirler. İşgücü verimliliğinin artması kısa vadede daha hızlı bir ekonomik büyümeye yol açmakta ancak iş imkânlarını kısıtlayabilmekte ve büyüme ile 
Yönetim ve Ekonomi Araştırmaları Dergisi / Journal of Management and Economics Research

Cilt/Volume: 15 Sayı/Issue: $3 \quad$ Ey/ül/September 2017 ss./pp. 114-131

C. Aydın Doi: http://dx.doi.org/10.11611/yead.333793

işsizlik arasındaki ilişkiyi tersine çevirebilmektedir (Boyer ve Petit, 1981; Havlik ve Landesmann, 2004; Belorgey vd., 2006 ve Marelli ve Signorelli, 2010). Rejim katsayıları büyüklük olarak dikkate alındığında, enflasyon oranının eşik değerin altında olduğu rejimde, ekonomik büyümenin işsizlik üzerindeki etkisinin üstünde olduğu rejime göre daha güçlü olduğu görülmektedir.

Tahmin edilen modelin bulguları kısaca şu şekilde özetlenebilmektedir; a) 2005-2015 dönemi için Türkiye'de bölgesel işsizlik düzeyi ile ekonomik büyüme arasındaki ilişkinin doğrusal olmadığı tespit edilmiştir. b) Enflasyon eşik değeri \%7.98 olarak bulunmuştur. Ayrıca, enflasyon oranının eşiğin altında gerçekleşmesi durumunda bölgesel işsizlik ile ekonomik büyüme arasında anlamlı ve negatif yönlü; eşiğin üzerinde gerçekleşmesi durumunda ise anlamlı ve pozitif yönlü bir ilişki tespit edilmiştir.

\section{SONUÇ}

Yüksek enflasyonun birçok ekonomik maliyeti olması nedeniyle düşük enflasyon hedefi ülkelerin en temel hedeflerinden biridir. Bu çalışmanın amacı hükümetlerin/merkez bankalarının tam istihdam hedefleri ile birlikte düşük enflasyon hedeflerini beraber sağlayıp sağlayamayacakları sorusuna cevap verebilmektir. Ayrıca, çalışmada bir ekonomide neden fiyat istikrarının sağlanması gerektiği gerekçeleriyle açıklanmakta, ayrıca fiyat istikrarı sağlanmış olsa bile, bunun kısa vadede makroekonomik açıdan ciddi gerilemeler yaşanmasını engellemeyeceği ortaya konulmaktadır. Yüksek enflasyon dönemlerinde ekonomik büyümenin işsizlik üzerindeki azaltıcı etkisi zayıflayabileceği gibi bu ilişki tersine dönebilmektedir. Bu bağlamda ekonomik büyümenin işsizlik üzerindeki etkisi ve enflasyon oranının bu ilişkideki rolü, Türkiye'nin 2005-2013 yıllarını kapsayan bölgesel veriler çerçevesinde incelenmiştir.

Ekonomik büyüme ile işsizlik arasındaki ilişkide enflasyonun rolü ve etkisini tespit edebilmek amacıyla ilk olarak seriler arasında yatay kesit bağımlılı̆̆ının olup olmadığı incelenmiştir. Sonrasında ise bu serilerin durağanlığı araştırılmıştır. Durağanlık testlerinin ardından çalışmada, serilerin doğrusal olmadığı ortaya konulmuş ve PYGR yaklaşımı ile yapılan sınama sonucunda enflasyon oranı için bir eşik olduğuna karar verilmiştir. Daha sonra PYGR modeli oluşturulmuş ve buna göre model tahmin edilmiştir. Tüm analiz dönemi için enflasyon oranına ilişkin eşik değeri \%7.98 olarak bulunmuştur. Ekonomik büyümenin hesaplanan eşik enflasyon oranı değerinin altında ve üstünde olması, işsizlik ile olan iliş̧isini etkilemektedir. Enflasyon düzeyi hesaplanan eşik değerin altında kaldığı, diğer bir değişle fiyat istikrarının sağlandığı bir ortamda negatif ve istatistiksel olarak anlamlı olan büyüme-işsizlik ilişkisi, enflasyonun eşik değerin üzerine çıkması ile birlikte pozitif ve istatistiksel olarak anlamlı bir ilişkiye dönüşmektedir.

Bu çalışmanın sonuçları, büyüme ile işsizlik arasında doğrusal ve ters yönlü bir ilişkinin olduğunu ifade eden yaklaşımların, ancak fiyat istikrarını sağlayan düşük bir enflasyon düzeyinde diğer bir deyişle 
Yönetim ve Ekonomi Araştırmaları Dergisi / Journal of Management and Economics Research

Cilt/Volume: 15 Sayı/Issue: $3 \quad$ Ey/ül/September 2017 ss./pp. 114-131

C. Aydın Doi: http://dx.doi.org/10.11611/yead.333793

enflasyon oranının eşik değerin altında bulunduğu durumlarda geçerli olabileceğini vurgulamaktadır. Bu bağlamda elde edilen bulgular, yüksek ekonomik büyüme ile birlikte düşük işsizlik oranlarını aynı anda sağlamak için enflasyonun eşik seviyesinin altında tutulması gerekliliği konusunda politikacılar için yararlı olacaktır. Böylece ekonomik hedefler bağlamında, tam istihdam hedefinin fiyat istikrarı hedefi ile çelişmeyeceği, fiyat istikrarının sağlanması ve korunmasının uzun dönemde büyüme ve istihdam için uygun ortamı oluşturarak işsizliğin azalmasına katkı sağlayacağı düşünülmektedir.

\section{KAYNAKÇA}

Akay, H. K., Aklan, N. A. ve Çınar, M. (2016) “Türkiye Ekonomisinde Ekonomik Büyüme ve İşsizlik”, Yönetim ve Ekonomi Araştırmaları Dergisi, 14(1), 209-226.

Akgül, I. ve Özdemir, S. (2012) “Enflasyon eşiği ve ekonomik büyümeye etkisi”, İktisat İşletme ve Finans, 27(313), 85-106.

Aksu, H. ve Başar, S. (2016). "Dynamic Effects of Output on Unemployment in Turkish Economy", Atatürk Üniversitesi Sosyal Bilimler Enstitüsü Dergisi, 20(1).

Ataman, B. C. (2006) “Türkiye'de 2000-2005 Dönemi İşsizlik Üzerine Tartışmalar”, İktisat İşletme ve Finans, 21(239),93-107. doi: 10.3848/iif.2006.239.4644

Aydın, C. Akıncı, M. ve Yılmaz, Ö. (2017) "Ekonomik Büyüme Dinamizmini Enflasyon Ne Zaman Engeller? Yükselen Ekonomiler Üzerine Bir Dinamik Panel Eşik Modeli”, İktisadi ve İdari Bilimler Fakültesi Dergisi, 18(3), 748-761.

Aydın, C. ve Esen, Ö. (2017) "Inflationary Threshold Effects in the Relationship between Unemployment and Economic Growth: Evidence from Turkey", International Journal of Economic Perspectives, 11(2).

Aydin, C. ve Odabasioglu, F. G. (2017) "Financial Development and Economic Growth: The Case of Turkey and Romania", International Journal of Academic Research in Business and Social Sciences, 7(6), 23-38.

Barışık, S., Çevik, E. İ. ve Çevik, N. K. (2010) “Türkiye'de Okun yasası, asimetri ilişkisi ve istihdam yaratmayan büyüme: Markov-switching yaklaşımı”, Maliye Dergisi yayınları, 159, 88-102.

Bayrak, M. ve Esen, Ö. (2013) "Examining the Policies in Turkey That Have Been Implemented during the Structural Reform Process from the Standpoint of Growth-Unemployment", International Journal of Economics and Finance, 5(6), 134-150. doi: 10.5539/ijef.v5n6p134 
Yönetim ve Ekonomi Araştırmaları Dergisi / Journal of Management and Economics Research

Cilt/Volume: 15 Sayı/Issue: $3 \quad$ Eylül/September $2017 \quad$ ss./pp. 114-131

C. Aydın Doi: http://dx.doi.org/10.11611/yead.333793

Belorgey, N., Lecat, R. ve Maury, T. P. (2006) "Determinants of Productivity per Employees: An Empirical Estimation Using Panel Data", Economics Letters, 91(2), 153-157. doi:10.1016/j.econlet.2005.09.003

Boyer, R. ve Petit, P. (1981) "Employment and Productivity in the EEC", Cambridge Journal of Economics, 5(1), 47-58.

Breusch, T. S. ve Pagan, A. R. (1980) "The Lagrange multiplier test and its applications to model specification in econometrics", The Review of Economic Studies. 47(1), 239-253.

Ceylan, S. ve Şahin, B. Y. (2010) "İşsizlik ve Ekonomik Büyüme İlişkisinde Asimetri”, Doğuş Üniversitesi Dergisi, 11(2), 157-165.

Dornbusch, R. ve Fischer, S.(1998) “Makro Ekonomi”, McGraw Hill-Akademi, İstanbul.

Esen, O., Aydin, C. ve Aydin, R. (2016) "Inflation threshold effect on economic growth in Turkey", Journal of Advanced Research in Law and Economics, 7(8), 1983-1993.

Fouquau, J., Hurlin, C. ve Rabaud, I. (2008) “The Feldstein-Horioka Puzzle: A Panel Smooth Transition Regression Approach”, Economic Modelling, 25, 284-299.

Gonzalez, A., Terasvirta, T., ve van Dijk, D. (2005) "Panel Smooth Transition Regression Model and an Application to Investment Under Credit Constraint", Working Paper in Economics and Finance, Stockholm School of Economics, Vol. 64.

Güloğlu, B. ve Nazlioglu, Ş. (2013) "Impacts of Inflation on Agricultural Prices: Panel Smooth Transition Regression Analysis”, Siyaset, Ekonomi ve Yönetim Araştırmaları Dergisi, 1(1).

Hansen, B. E. (1999) "Threshold Effects in Non-Dynamic Panels: Estimation, Testing and Inference", Journal of Econometrics ,93, 345-368.

Havlik, P. ve Landesmann, M. (2004) "Structural change, productivity and employment in the new EU member states" (No. 313), Vienna Institute for International Economic Studies.

Kara, M. ve Duruel, M. (2005) “Türkiye'de Ekonomik Büyümenin İstihdam Yaratamama Sorunu”, Sosyal Siyaset Konferansları Dergisi, (50), 367-396.

Kılıç, C. (2003) “Türkiye’de İşsizlik ve Avrupa İstihdam Stratejisi”, TİSK İşveren Dergisi, 42(1).

Knotek II, E. S. (2007) “How useful is Okun's law?”, Economic Review-Federal Reserve Bank of Kansas City, 92(4), 73.

Marelli, E. ve Signorelli, M. (2010) "Employment, Productivity and Models of Growth in the EU", International Journal of Manpower, 31(7), 732-754. doi: 10.1108/01437721011081572 
Yönetim ve Ekonomi Araştırmaları Dergisi / Journal of Management and Economics Research

Cilt/Volume: 15 Sayı/Issue: $3 \quad$ Ey/ül/September 2017 ss./pp. 114-131

C. Aydın Doi: http://dx.doi.org/10.11611/yead.333793

Moon, H. R. ve Perron, B. (2004) "Testing for a unit root in panels with dynamic factors", Journal of Econometrics, 122(1), 81-126.

Pesaran, M. H. (2004) "General diagnostic tests for cross section dependence in panels", CESifo Working No. 1229.

Pesaran, M. H., Ullah, A. ve Yamagata, T. (2008) "A bias- adjusted LM test of error cross- section independence", The Econometrics Journal. 11(1), 105-127.

Phillips, A. W. (1958) "The Relation between unemployment and the rate of change of money wage rates in the United Kingdom, 1861-1957”, economica, 25(100), 283-299. doi: 10.1111/j.14680335.1958.tb00003.x

Şentürk, M. ve Akbaş, Y. E. (2014) "İşsizlik-Enflasyon ve Ekonomik Büyüme Arasındaki Karşılıklı İlişkinin Değerlendirilmesi: Türkiye Örneği”, Journal of Yaşar University, 9(34), 5820-5832. doi: $10.19168 /$ jyu. 43548

TCMB (2013). “Enflayon ve Fiyat İstikrarı”, Ankara: Türkiye Cumhuriyet Merkez Bankası.

White, W. R. (2006) “Is Price Stability Enough?”, BIS Working Papers, (2005). Basel: Bank for International Settlements Press \& Communications.

Yılmaz, Ö. G. (2005) “Türkiye Ekonomisinde Büyüme İle İşsizlik Oranları Arasındaki Nedensellik İlişkisi”, Ekonometri ve İstatistik, (2),63-76.

Yüceol, H. M. (2006) “Türkiye Ekonomisinde Büyüme ve İşsizlik İlişkisinin Dinamikleri”, İktisat İşletme ve Finans, 21(243), 81-95. doi: 10.3848/iif.2006.243.5524 